\title{
Primary Sclerosing Cholangitis - Current Issues in Clinical Practice
}

\author{
L. Corless ${ }^{1,2}$ and H. Tsai ${ }^{*}, 1$ \\ ${ }^{I}$ Department of Gastroenterology, Castle Hill Hospital, Cottingham, UK \\ ${ }^{2}$ Leeds Institute of Molecular Medicine, University of Leeds, Leeds, UK
}

\begin{abstract}
Aims: To review current issues in the diagnosis and treatment of primary sclerosing cholangitis.
Methods: search of PubMed using the terms "primary sclerosing cholangitis", "PSC", "cholangitis" and "cholestasis", as well as by review of current guidelines from the major international liver societies.

Results: Primary sclerosing cholangitis is still a challenging condition to diagnose and manage, but newer imaging modalities like MRCP and timing of liver transplantation point the way forward.
\end{abstract}

Keywords: Primary sclerosing cholangitis, ulcerative colitis.

\section{INTRODUCTION}

Primary sclerosing cholangitis (PSC) is defined as a chronic cholestatic disorder, characterised by progressive inflammation and subsequent fibrosis of both the intra- and extrahepatic bile ducts. PSC is relatively uncommon, which has limited the ability of researchers to fully understand and elucidate many aspects of the disease. Clinicians responsible for managing patients with PSC are faced with numerous dilemmas, in particular what constitutes optimal medical therapy, when to consider referral to specialist transplantation centres and how to manage and reduce cancer risk. This review aims to provide an up to date overview of PSC, with particular emphasis on medical management and understanding cancer risk. A literature review was undertaken by searching PubMed using the terms "primary sclerosing cholangitis", "PSC", "cholangitis" and "cholestasis", as well as by review of current guidelines from the major international liver societies.

\section{EPIDEMIOLOGY AND PATHOGENESIS}

Overall incidence of PSC is estimated between 0.9 and 1.3 cases per 100,000 individuals and prevalence 8.5 - 13.6 per 100,000 individuals [1-3]. A geographical variation exists, with northern European and American societies exhibiting higher rates of PSC than southern regions and Asia [1-4]. Middle aged men account for the majority $(>60$ $\%)$ of cases and most of those diagnosed (60 - 80\%) have a previous diagnosis of inflammatory bowel disease (IBD) [5].

Pathogenesis is incompletely understood but appears to be dependent on interplay of immune and inflammatory phenomena occurring in genetically susceptible individuals.

First degree relatives and siblings are at a significantly increased risk of developing PSC, although no specific pattern of inheritance exists [6]. This suggests that the

*Address correspondence to this author at the Department of Gastroenterology, Castle Hill Hospital Cottingham UK; Tel: 7880508381; Fax: 1482622207; E-mail: hhtsai @ doctors.org.uk genetic susceptibility stems from inheritance of major histocompatibility complex (MHC) alleles and other polymorphisms, but no alleles have been identified which are absolutely required for disease development [7]. The presence of autoantibodies, particularly perinuclear antineutrophil cytoplasmic antibodies (pANCA), has led to speculation that there is an autoimmune component, although the poor correlation of serology with clinical features, and the limited response of PSC to immunosuppressive therapy in general, indicates that this is not the solitary pathogenic process [8].

Although a specific role for infectious agents in causation of PSC has not been found, bacterial colonisation of the biliary tract is thought to adversely affect outcome [9]. The mechanism of injury is unclear but recently, pANCA was found to be directed against $\beta$-tubulin isotype 5 [10], which is cross reactive with a bacterially expressed protein, and hints at an abnormal immunological response to an infectious trigger playing a role in either the primary development or subsequent clinical manifestation of PSC.

\section{CLINICAL FEATURES}

Although many patients with PSC are asymptomatic at the time of diagnosis, classical symptoms such as jaundice, abdominal pain, fatigue and pruritis are often reported [11]. Many have hepatomegaly or splenomegaly, but only a small proportion $(<5 \%)$ will present with evidence of portal hypertension [5, 12, 13]. Rarely, patients will describe symptoms relating to recurrent cholangitis as the cardinal complaint [4].

Features of other autoimmune disorders, such as thyroid disease, are present in approximately $20 \%$ of cases [14] and PSC can additionally present as an autoimmune hepatitis (AIH) overlap syndrome in up to $8 \%$ of cases [15]. In keeping with other hepatobiliary disorders, osteopenic bone disease is more common than in the general population [16] and as such bone protection using calcium and vitamin D is routinely advised, alongside regular assessment of bone density [17]. 
The clinical course of PSC varies widely from largely asymptomatic disease, recurrent cholangitis, to rapidly progressive development of liver failure or cholangiocarcinoma $[18,19]$, and current prognostication systems cannot adequately determine which individuals are likely to run which course.

\section{DIAGNOSIS}

Diagnosis often follows detection of abnormal serum liver function tests, often but not always with a predominant abnormality of alkaline phosphatase [20], and is subsequently confirmed using a combination of serological antibody tests, radiological investigations, and histology. Serum tests include pANCA, which is positive in up to $80 \%$ [21] of those with PSC, although it can be detected in ulcerative colitis (UC) alone, as well as in autoimmune hepatitis. Additionally, anti-nuclear antibody (ANA) and anti smooth muscle antibodies can be found in up to half of those with PSC but are also non-specific. For this reason, serum antibodies are not sufficient in isolation to make a diagnosis of PSC [17].

Endoscopic retrograde cholangiopancreatography (ERCP) has historically been the gold standard for diagnosis, but can now be reasonably substituted for magnetic resonance cholangiopancreatography (MRCP), which has similar levels of sensitivity and specificity [22, 23], particularly since ERCP can result in hospital admission for $10 \%$ of PSC patients [24]. Classical radiological findings include dominant strictures and the multifocal stricturing/dilatation giving a characteristic beading pattern of the bile ducts [25]. It should be noted that similar appearances can also occasionally be seen in other disorders, including ischaemic biliopathy [26]. Where doubt exists, liver biopsy can be diagnostic, especially where typical radiological features are absent. The pathognomonic histological feature is concentric periductal fibrosis, resulting in the classical "onion skin" appearance, but this is not commonly observed [27] and may also be seen in secondary sclerosing cholangitis. Other histological features include portal lymphocyte infiltration and fibrosis, ductopenia and cholestasis, classified on a 4 point staging system [28]. Diagnostic features on histology in the absence of radiological evidence, is referred to as small duct PSC [29].

Liver biopsy is also useful where an overlap syndrome is suspected, due to particularly high levels of serum transaminase or IgG [17]. Other conditions which should be excluded before reaching a diagnosis of PSC include antimitochondrial antibody negative primary biliary cirrhosis (PBC), sarcoidosis, drug induced cholestatic liver injury [30] and causes of secondary sclerosing cholangitis such as chronic choledocholithiasis, IgG4-associated sclerosing cholangitis and HIV related cholangiopathy [11].

\section{ASSOCIATION WITH INFLAMMATORY BOWEL DISEASE}

Although only a small portion of those with IBD develop PSC [31], most patients with PSC have IBD. $70 \%$ have UC, but less than $10 \%$ have a diagnosis of Crohn's disease (CD) [5], but exclusively small bowel CD does not appear to be associated with PSC at all [32].
The pattern of IBD in those with PSC is different to those without liver disease. In $\mathrm{CD}$, those with PSC have significantly less fistulating disease, strictures or the need for bowel surgery [33] than matched controls. In those with UC and PSC, despite having more extensive disease, with a greater preponderance of backwash ileitis, the clinical course is associated with rectal sparing, is more quiescent, and requires less pharmacological therapy than controls $[34,35]$.

No clear correlation exists between the severity of bowel and liver disease, with reports of liver disease being both precipitated by colectomy [36] and total colectomy being protective against PSC recurrence post liver transplantation [37]. These discrepancies may be due in part to the small cohorts of PSC patients historically available to researchers. There is currently no evidence to support routine proctocolectomy in liver transplant recipients [38].

In those with PSC where no diagnosis of IBD has previously been made, a screening colonoscopy and biopsies should be undertaken [29]. There is no current guidance as to whether colonoscopy should be repeated if the index investigation shows no evidence of IBD.

\section{COMPLICATIONS}

\section{Cancer}

In common with many other chronic inflammatory conditions, cancer risk is increased in PSC, specifically those of the hepatobiliary tract and large bowel. The largest study to date [39] was conducted in Sweden and compared over 600 individuals with PSC with the general population. Cancer accounted for $44 \%$ of the deaths in the cohort overall. Hepatobiliary cancers (comprising cholangiocarcinoma, hepatocellular carcinoma (HCC), and cancer of the gallbladder) occurred in $13.3 \%$ of the PSC group over a 5 year period, a 160 fold increase in risk over controls. The risk of colorectal and pancreatic cancers was 10 and 14 fold higher respectively. The increase in pancreatic cancer incidence is surprising, as higher risk of developing this form of cancer has not previously been associated with PSC. According to other reviewers, the study may have misclassified distal common bile duct cancers as pancreatic in origin, leading to the increased rate reported [40].

Cholangiocarcinoma is reported to occur in $8-13.2 \%$ of those with PSC [5,7], with an annual incidence of $1.5 \%$ per year [39] and is often fatal, with 5 year survival rates of less than $10 \%[19,41]$. It can develop within the liver and common bile duct, but is most frequently identified at the hilar region [7]. Triggers for the development of cholangiocarcinoma are uncertain, but may include duration of IBD, particularly if there is a history of colorectal dysplasia or neoplasia [42]. In contrast, duration of PSC does not appear to be a significant factor, with many diagnosed with cholangiocarcinoma within the first year of PSC diagnosis [1], although this may reflect a chronic, asymptomatic course of PSC in these individuals, rather than true early onset cancer. Other factors in cancer development may include up-regulation of numerous pro-inflammatory cytokines and subsequent oxidative stress with consequent mutation of various oncogenes [43, 44] which have been reported in a number of studies. 
Since rates of cholangiocarcinoma incidence are relatively high in PSC, many clinicians wish to screen patients in order to improve detection and treatment rates.

Levels of carbohydrate antigen (CA) 19-9 are higher in those with cholangiocarcinoma than those with PSC alone [45] at a population level, however screening using CA 19-9 in isolation cannot currently be advocated. Firstly, CA 19-9 is often raised in acute cholangitis or dominant stricture disease [46], and secondly it commonly only identifies cholangiocarcinoma at a late stage [47] after the opportunity for effective treatment has passed. Furthermore, $7 \%$ of the population who are Lewis antigen negative are also CA 19-9 negative, which may give false reassurance if tested [48]. Finally, no clear cut-off value exists to differentiate between PSC and advent of cholangiocarcinoma within individuals. Combinations of serum markers, radiology, and evolving cytological techniques such as fluorescent in situ hybridisation, show promise but are currently unvalidated [49]. Until larger population based trials are conducted to assess such screening programmes, it is impossible to discern whether such interventions are associated with a survival benefit, or whether they are cost-effective. In the absence of evidence based guidelines, an excellent review of cancer screening in PSC [40] recently presented a working guideline, incorporating annual MRCP/MRI scanning and CA 19-9 measurement, with subsequent ERCP and brush cytology in those with either a dominant stricture or raised CA 19-9. ERCP should also be undertaken where there has been a significant progression of cholestasis clinically or biochemically [40].

Cancer of the gallbladder is thought to be at least 10 times more prevalent in those with PSC than the general population [50]. Current international guidelines recommend annual ultrasound scanning to assess the gallbladder, since lesions in the gallbladder in those with PSC are frequently due to adenocarcinoma formation [50, 51]. Cholecystectomy is advised for all masses detected, even those under $1 \mathrm{~cm}$ in size [17], but must be carefully considered given the increased risk of surgery in those with chronic liver disease.

Cirrhosis due to any cause, including PSC is associated with increased risk of developing $\mathrm{HCC}$, although current recommendations state that formal surveillance should only occur where the anticipated incidence is greater than $1.5 \%$ per year [52]. This is not thought to be the case in PSC and as such, many liver units do not routinely offer $\mathrm{HCC}$ surveillance to this group.

The increased risk of colorectal dysplasia and cancer, particularly on the right side of the colon [53], in those with PSC and UC is well established [42, 54], providing the rationale for annual or biennial colonoscopic surveillance in those with pan-colitis and PSC [17]. The association with Crohns disease (CD) is less clear. Two small cohorts have recently reported on cancer risk in PSC with CD. In a British cohort, the increased risk in PSC with UC was confirmed, but no significant increase in dysplasia or malignancy was seen in those with colonic CD [55]. In contrast, a Swedish group analysed every patient diagnosed with colonic CD and PSC over almost thirty years, which resulted in a cohort of 28 patients. Against matched controls with no PSC, a significantly higher number of those with PSC developed colonic dysplasia or malignancy ( $9 v s 3$ patients, OR 6.78, $95 \%$ CI 1.65-27.9, $P=0.016$ ) [33].

In those with IBD, detection of colorectal dysplasia often leads to consideration of panproctocolectomy. Previous studies have indicated that the risk of progression from low to high grade dysplasia and neoplasia is even greater in those with concurrent PSC [56], and so a strategy advocating early surgery may be justified, although these observations must be tempered against findings of other studies suggesting a swifter progression of PSC post panproctocolectomy [57]. As previously stated, the risk of surgery in PSC, particularly where cirrhosis is present, must be considered, particularly where only low grade colonic dysplasia is detected. Furthermore, an increased risk of pouchitis has been identified in those with PSC who undergo ileal pouch formation [58], and there is an increased incidence of peristomal varix formation [59], which may be difficult to manage without transjugular intrahepatic portosystemic shunting or liver transplantation [58].

In conclusion, PSC unquestionably raises the risk of hepatobiliary malignancy, and colorectal cancer (CRC) risk in UC. It is unclear at present whether CD incurs similar risk, although the cumulative lifetime risk of CRC in those with UC and colonic CD is thought to be similar [60] and international societies currently recommend screening in all patients with IBD and evidence of colonic involvement [17, 29].

\section{Cholangitis}

The mortality rate of acute cholangitis can approach 10 $\%$ in high risk populations, which includes those with PSC [61]. Bile is sterile in normal biliary tracts but bacteria can enter via the ampulla after sphincterotomy or stenting, or via portal bacteraemia occurring due to translocation of bacteria through hepatic sinusoids and the space of Disse. Bacterobilia will not necessarily result in cholangitis [62] but where it does, cholangitis will usually manifest with symptoms such as abdominal pain, fever, and jaundice Charcot's triad [61]. In PSC, bacterial cholangitis is often a consequence of poor biliary drainage following stricture formation. Dominant strictures, which occur in approximately half of people with PSC [63], and biliary sepsis are both associated with poorer outcomes [64]. Treatment should focus on clearance of the duct, usually by ERCP with or without stent placement. This also allows brushings to be taken for cytology, in order to exclude development of cholangiocarcinoma.

The role of bacterial infection in the course of PSC itself is less well understood. A previous study investigating the relationship of bacterobilia and progression of PSC took bile samples at the time of ERCP in a cohort of patients with and without dominant strictures [9]. Enteric bacteria were detected in $40 \%$ of PSC patients with dominant stricture but never in the absence of dominant stricture $(P=0.004)$. Follow up ERCP showed persistence of identical strains of bacteria in the majority of those with dominant stricture, despite antibiotic therapy. This suggests that bacterobilia is a frequent finding in those with dominant stricture and that short courses of antibiotics may not be effective in eradicating bacterobilia, or perhaps that it is more difficult for those with PSC to clear bacteria effectively from ducts 
[9]. Since recurrent cholangitis in PSC is associated with poor outcome, it is considered appropriate to offer prophylaxis in context of recurrent infections [17]. Failure to control cholangitis with antibiotics should prompt referral to a transplant centre for assessment [65]. The fact that bacterobilia may adversely influence disease progression also raises the question of whether prophylaxis should be initiated after the first episode of bacterial cholangitis, although no evidence is currently available. Furthermore, there is no evidence to support or refute the use of rotational antibiotics and this and other questions pertaining to long term antibiotic use are probably best addressed at a local level in liaison with microbiological expertise.

\section{Portal Hypertension}

Portal hypertension can occasionally present in PSC before the onset of cirrhosis, since fibrosis can occur in a predominantly presinusoidal distribution [65]. Complications of portal hypertension should be managed as for other liver diseases, although since significant portal hypertension can occur early in the disease, it may be prudent to consider screening for oesophageal varices in those with high bilirubin or low platelet count, even in the absence of cirrhosis.

\section{Other Common Complications}

Deficiency of fat soluble vitamins is well recognised, in common with other cholestatic diseases, and any deficiency should be replaced appropriately [29].

Pruritis may signal the development of a dominant stricture and should therefore be investigated with imaging in the first instance. In those without dominant stricture, treatment should proceed as for other cholestatic diseases, with trials of a selection of anti-pruritic medications [66]. Plasmapheresis has been used for the treatment of itch with varying results, and occasionally intractable pruritis will be the primary indication for liver transplant assessment [17. 29].

\section{MANAGEMENT}

No therapeutic interventions other than liver transplantation have to date been proven to slow progression of PSC. Many drugs have been evaluated, including corticosteroids, anti-metabolites and calcineurin inhibitors, but none have been shown to have lead to significant improvements in outcome measures [29].

\section{Ursodeoxycholic Acid (UDCA)}

Ursodeoxycholic acid (UDCA) is a synthetic hydrophilic bile acid recommended for use in primary biliary cirrhosis [67], which is the most commonly used drug in PSC.

European and American international guidelines do not currently advocate the routine use of UDCA in PSC [17, 29]. Despite good evidence that $15-20 \mathrm{mg} / \mathrm{kg} / \mathrm{d}$ leads to improvements in serum biochemistry [66], no survival benefit has been observed.

As there is some data to suggest that UDCA at this dose may reduce risk of colorectal cancer development, the European guidelines recommend giving consideration to using UDCA in those at especially high risk of cancer development [29].
Since publication of these guidelines, further studies and meta-analyses have been conducted. One study investigating high dose $(28-30 \mathrm{mg} / \mathrm{kg} / \mathrm{d})$ UDCA use showed significantly increased rates of death, decompensation and cholangiocarcinoma in the treated group, and was terminated early [68]. To further investigate the potential benefit of UDCA in colorectal cancer prevention, a nested cohort study was performed on a sub-group of the trial to determine the effect of UDCA for this indication. This unexpectedly showed a significant increase in neoplastic risk in those with PSC and UC [69], although it should be noted that the increase was due to a higher rate of low grade dysplasia, whilst rates of high grade dysplasia and cancer were similar in both groups.

Most recently, a meta-analysis and Cochrane review have also been published. 8 randomised clinical trials involving over 500 patients, including the study discussed above, were analysed. These reviews found no significant difference in any outcome between low or high dose UDCA and no intervention $[70,71]$. The Cochrane review concluded that although UDCA did not reduce rates of death, decompensation, or lead to radiological or histological improvement of PSC, administration did lead to significant improvements in serum liver enzyme levels and bilirubin. They considered UDCA to be well tolerated and safe, but could not find sufficient evidence to support or refute routine use of UDCA in PSC.

\section{Other Drugs}

Immunosupression with corticosteroids or antimetabolites is probably only of value in selected cases of AIH/PSC overlap syndromes, which manifest with a predominant immune component, as evidenced by high aminotransferase or circulating serum IgG levels. In PSC alone, both the limited efficacy and the increased risk of severe biliary sepsis, caution against the generalised use of these drugs $[29,72]$.

\section{ERCP}

Sudden deteriorations in liver function in PSC often herald the development of a dominant stricture, which should be managed endoscopically [73], as endoscopic treatment improves survival when compared to expected outcomes using prognostic models such as the Mayo score $[74,75]$. This was corroborated by another group who performed a retrospective case review of their PSC cohort recently [76].

At ERCP, brushings should always be taken of new strictures to exclude cholangiocarcinoma or high grade dysplasia, which is occasionally managed aggressively by liver transplantation. Where ERCP is not feasible, usually due to a proximal stricture, percutaneous cholangiography should be considered [17]. It is recommended that all biliary interventions in individuals with PSC are covered with prophylactic antibiotics, according to local microbiological protocols, since injection of contrast into an obstructed biliary tree can cause cholangitis $[17,29]$. There is also a role for surgery in the small group for whom ERCP and PTC are not feasible and this should be discussed with specialist hepatobiliary surgical centres [17]. 


\section{Liver Transplantation}

Transplantation outcomes are generally good, with 10 year survival rates of approximately 70\% [77], although PSC recurrence is seen in up to a quarter of recipients [78]. Indications for transplantation in PSC include liver failure, complications of portal hypertension, recurrent cholangitis and intractable pruritis [79]. A Roux-en-Y approach is favoured as it reduces rates of anastamotic stricture formation and may improve survival [80]. Timing of transplantation is challenging in PSC for numerous reasons [81]. Often, the degree of liver failure is mild compared with other diseases and is therefore not well selected using classical scoring systems such as the model for end-stage liver disease (MELD) [82]. Secondly, cholangiocarcinoma can manifest even in asymptomatic individuals, is frequently difficult to detect [83], and no validated screening strategy exists. Finally, septic complications can lead to both rapid deterioration in clinical and biochemical status, and increase the risk of surgery because of ongoing biliary sepsis. For these reasons, it has been advised that individuals with PSC are managed from an early stage by liver transplant centres, where a higher volume of patients are seen and timing of transplant may be more likely to be optimal $[7,82]$.

\section{Treatment of Cholangiocarcinoma}

Resection of cholangiocacinoma is possible, but is usually only undertaken in those with no cirrhosis, despite which survival rates are only approximately $20 \%$ at 3 years [84]. Other options include chemotherapy followed by liver transplantation but the number of patients who are eligible is small [85].

\section{PROGNOSIS}

The estimated median survival from time of diagnosis to death or transplantation is between 7 and 12 years $[5,11]$ and long term survival is reduced even in asymptomatic individuals [5]. All-cause mortality is increased in patients with PSC [86] with cholangiocarcinoma and liver failure the commonest causes of death [7]. Despite many advances in the understanding of PSC, mortality rates have not improved a great deal over the last 25 years [11] which suggests that clinical management in this group remains suboptimal and much remains to be done to improve prognosis. Prediction of prognosis is challenging, although serum bilirubin concentration, and histological stage at the time of diagnosis are known to be independent predictors of poor prognosis [5], and a selection of prognostic models have been described, including the Mayo model [75], which may be more accurate in predicting outcome in PSC than other scores such as Childs-Pugh [87]. There is however no robust evidence that such models accurately stratify disease progression and they are not currently recommended for general use [17].

\section{CONCLUSIONS AND FUTURE PERSPECTIVES}

PSC remains a disorder which presents numerous dilemmas for clinicians, largely because it is poorly understood, and therefore harder to treat, when compared with most other hepatic diseases.

A major priority for PSC research is to more fully discern the precise pathogenesis of the condition. Improved understanding of the complex interplay of genetic, immunological, and exogenous factors is likely to yield many potential novel therapeutic targets. Meanwhile, it is vitally important that current medical therapeutic options, particularly UDCA, are fully and robustly evaluated. A national randomised controlled trial evaluating the role of UDCA in PSC would be of great benefit whilst progress continues in identifying the underlying pathogenic mechanisms. A large trial of this kind may also facilitate a larger scale assessment of cancer risk, and an opportunity to refine prognostic models for PSC. This may allow a more streamlined approach to referral to specialist services and a more unified approach to timing of transplantation.

Most urgently, methods of identifying cholangiocarcinoma at an early stage are desperately needed, whether by discovery of novel biomarkers using genome wide association studies, or by refining the interpretation of currently available tumour markers such as CA 19-9. Prevention and early treatment of cholangiocarcinoma in PSC would make tremendous in-roads to reducing the unacceptable levels of mortality currently suffered by this challenging and fascinating group of individuals.

\section{CONFLICT OF INTEREST}

The authors confirm that this article content has no conflicts of interest.

\section{ACKNOWLEDGEMENTS}

Declared none.

\section{REFERENCES}

[1] Boberg, K.M.; Aadland, E.; Jahnsen, J.; Raknerud, N.; Stiris, M.; Bell, H. Incidence and prevalence of primary biliary cirrhosis, primary sclerosing cholangitis, and autoimmune hepatitis in a Norweigan population. Scand. J. Gastroenterol., 1998, 33, 99-103.

[2] Bambha, K.; Kim, W.R.; Talwalkar, J.; Torgerson, H.; Benson, J.T.; Therneau, T.M.; Loftus, E.V. Jr.; Yawn, B.P.; Dickson, E.R.; Melton, L.J., 3rd. Incidence, clinical spectrum, and outcomes of primary sclerosing cholangitis in a United States community. Gastroenterology, 2003, 125, 1364-1369.

[3] Kingham, J.G.; Kochar, N.; Gravenor, M.B. Incidence, clinical patterns, and outcomes of primary sclerosing cholangitis in South Wales, United Kingdom. Gastroenterology, 2004, 126, 1929-1930.

[4] Kaplan, G.G.; Laupland, K.B.; Butzne, R.D.; Urbanski, S.J.; Lee, S.S. The burden of large and small duct primary sclerosing cholangitis in adults and children: a population-based analysis. Am. J. Gastroenterol., 2007, 102, 1042-1049.

[5] Broomé, U.; Olsson, R.; Lööf, L.; Bodemar, G.; Hultcrantz, R.; Danielsson, A.; Prytz, H.; Sandberg-Gertzén, H.; Wallerstedt, S.; Lindberg, G. Natural history and prognostic factors in 305 Swedish patients with primary sclerosing cholangitis. Gut, 1996, 38, 610615.

[6] Bergquis, T.A.; Lindberg, G.; Saarinen, S.; Broome, U. Increased prevalence of primary sclerosing cholangitis among first-degree relatives. J. Hepatol., 2005, 42, 252-256.

[7] Weismüller, T.J.; Wedemeyer, J.; Kubicka, S.; Strassburg, C.P.; Manns, M.P. The challenges in primary sclerosing cholangitis-aetiopathogenesis, autoimmunity, management and malignancy. $J$. Hepatol., 2008, 48(Suppl 1), S38-S57.

[8] Worthington, J.; Cullen, S.; Chapman, R. Immunopathogenesis of primary sclerosing cholangitis. Clin. Rev. Allergy Immunol., 2005, 28, 93-103.

[9] Pohl, J.; Ring, A.; Stremmel, W.; Stiehl, A. The role of dominant stenoses in bacterial infections of bile ducts in primary sclerosing cholangitis. Eur. J. Gastroenterol. Hepatol., 2006, 18, 69-74.

[10] Terjung, B.; Söhne, J.; Lechtenberg, B.; Gottwein, J.; Muennich, M.; Herzog, V.; Mähler, M.; Sauerbruch, T.; Spengler, U. pANCAs in autoimmune liver disorders recognise human beta- 
tubulin isotype 5 and cross-react with microbial protein FtsZ. Gut, 2010, 59, 808-816.

[11] Mendes, F.; Lindor, K.D. Primary sclerosing cholangitis: overview and update. Nat. Rev. Gastroenterol. Hepatol., 2010, 7, 611-619.

[12] Talwalkar, J.A.; Lindor, K.D. Primary sclerosing cholangitis. Inflamm. Bowel. Dis., 2005, 11, 62-72.

[13] Bergquist, A.; Said, K.; Broome, U. Changes over a 20-year period in the clinical presentation of primary sclerosing cholangitis in Sweden. Scand. J. Gastroenterol., 2007, 42, 88-93.

[14] Saarinen, S.; Olerup, O.; Broome, U. Increased frequency of autoimmune diseases in patients with primary sclerosing cholangitis. Am. J. Gastroenterol., 2000, 95, 3195-3199.

[15] Kaya, M.; Angulo, P.; Lindor, K.D. Overlap of autoimmune hepatitis and primary sclerosing cholangitis: an evaluation of a modified scoring system. J. Hepatol., 2000, 33, 537-542.

[16] Hay, J.E.; Lindor, K.D.; Wiesner, R.H.; Dickson, E.R.; Krom, R.A.; LaRusso, N.F. The metabolic bone disease of primary sclerosing cholangitis. Hepatology, 1991, 14, 257-261.

[17] Chapman, R.; Fevery, J.; Kalloo, A.; Nagorney, D.M.; Boberg, K.M.; Shneider, B.; Gores, G.J. Diagnosis and management of primary sclerosing cholangitis. Hepatology, 2010, 51, 660-678.

[18] Chapman, R.W.; Burroughs, A.K.; Bass, N.M.; Sherlock, S. Longstanding asymptomatic primary sclerosing cholangitis: report of three cases. Dig. Dis. Sci., 1981, 26, 778-782.

[19] Rosen, C.B.; Nagorney, D.M.; Wiesner, R.H.; Coffey, R.J., Jr.; LaRusso, N.F. Cholangiocarcinoma complicating primary sclerosing cholangitis. Ann. Surg., 1991, 213, 21-25.

[20] Chapman, R.W.; Arborgh, B.A.; Rhodes, J.M.; Summerfield, J.A.; Dick, R.; Scheuer, P.J.; Sherlock, S. Primary sclerosing cholangitis: a review of its clinical features, cholangiography, and hepatic histology. Gut, 1980, 21, 870-877.

[21] Bansi, D.S.; Fleming, K.A.; Chapman, R.W. Importance of antineutrophil cytoplasmic antibodies in primary sclerosing cholangitis and ulcerative colitis: prevalence, titre, and IgG subclass. Gut, 1996, 38, 384-389.

[22] Fulcher, A.S.; Turner, M.A.; Franklin, K.J.; Shiffman, M.L.; Sterling, R.K.; Luketic, V.A.; Sanyal, A.J. Primary sclerosing cholangitis: evaluation with MR cholangiography-a case-control study. Radiology, 2000, 215, 71-80.

[23] Textor, H.J.; Flacke, S.; Pauleit, D.; Keller, E.; Neubrand, M.; Terjung, B.; Gieseke, J.; Scheurlen, C.; Sauerbruch, T.; Schild, H.H. Three-dimensional magnetic resonance cholangiopancreatography with respiratory triggering in the diagnosis of primary sclerosing cholangitis: comparison with endoscopic retrograde cholangiography. Endoscopy, 2002, 34, 984-990.

[24] Bangarulingam, S.Y.; Gossard, A.A.; Petersen, B.T.; Ott, B.J.; Lindor, K.D. Complications of endoscopic retrograde cholangiopancreatography in primary sclerosing cholangitis. Am. J.Gastroenterol., 2009, 104, 855-860.

[25] MacCarty, R.L.; LaRusso, N.F.; Wiesner, R.H.; Ludwig, J. Primary sclerosing cholangitis: findings on cholangiography and pancreatography. Radiology, 1983, 149, 39-44.

[26] Gelbmann, C.M.; Rümmele, P.; Wimmer, M.; Hofstädter, F.; Göhlmann, B.; Endlicher, E.; Kullmann, F.; Langgartner, J.; Schölmerich, J. Ischemic-like cholangiopathy with secondary sclerosing cholangitis in critically ill patients. Am. J. Gastroenterol., 2007, 102, 1221-1229.

[27] Burak, K.W.; Angulo, P.; Lindor, K.D. Is there a role for liver biopsy in primary sclerosing cholangitis? Am. J. Gastroenterol., 2003, 98, 1155-1158.

[28] Ludwig, J.; Barham, S.S.; LaRusso, N.F.; Elveback, L.R.; Wiesner, R.H.; McCall, J.T. Morphologic features of chronic hepatitis associated with primary sclerosing cholangitis and chronic ulcerative colitis. Hepatology, 1981, 1, 632-640.

[29] Beuers, U.; Boberg, K.M.; Chapman, R.W.; Chazouillères, O.; Invernizzi, P.; Jones, D.E.; Lammert, F.; Parès, A.; Trauner, M. EASL Clinical Practice Guidelines: management of cholestatic liver diseases.European Association for the Study of the Liver. $J$. Hepatol., 2009, 51, 237-267.

[30] Kim, W.R.; Ludwig, J.; Lindor, K.D. Variant forms of cholestatic diseases involving small bile ducts in adults. Am. J. Gastroenterol., 2000, 95, 1130-1138.

[31] Olsson, R.; Danielsson, A.; Järnerot, G.; Lindström, E.; Lööf, L.; Rolny, P.; Rydén, B.O.; Tysk, C.; Wallerstedt, S. Prevalence of primary sclerosing cholangitis in patients with ulcerative colitis. Gastroenterology. 1991, 100, 1319-1323.
[32] Rasmussen, H.H.; Fallingborg, J.F.; Mortensen, P.B.; Vyberg, M.; Tage-Jensen, U.; Rasmussen, S.N. Hepatobiliary dysfunction and primary sclerosing cholangitis in patients with Crohn's disease. Scand. J. Gastroenterol., 1997, 32, 604-610.

[33] Lindström, L.; Lapidus, A.; Ost, A.; Bergquist, A. Increased risk of colorectal cancer and dysplasia in patients with Crohn's colitis and primary sclerosing cholangitis. Dis. Colon Rectum., 2011, 54, 1392-1397.

[34] Loftus, E.V., Jr.; Harewood, G.C.; Loftus, C.G.; Tremaine, W.J.; Harmsen, W.S.; Zinsmeister, A.R.; Jewell, D.A.; Sandborn, W.J. PSC-IBD: a unique form of inflammatory bowel disease associated with primary sclerosing cholangitis. Gut, 2005, 54, 91-96.

[35] Moayyeri, A.; Daryani, N.E.; Bahrami, H.; Haghpanah, B.; Nayyer-Habibi, A.; Sadatsafavi, M. Clinical course of ulcerative colitis in patients with and without primary sclerosing cholangitis. J. Gastroenterol. Hepatol., 2005, 20, 366-370.

[36] Cangemi, J.R.; Wiesner, R.H.; Beaver, S.J.; Ludwig, J.; MacCarty, R.L.; Dozois, R.R.; Zinsmeister, A.R.; LaRusso, N.F. Effect of proctocolectomy for chronic ulcerative colitis on the natural history of primary sclerosing cholangitis. Gastroenterology, 1989, 96, 790794.

[37] Alabraba, E.; Nightingale, P.; Gunson, B.; Hubscher, S.; Olliff, S.; Mirza, D.; Neuberger, J. A re-evaluation of the risk factors for the recurrence of primary sclerosing cholangitis in liver allografts. Liver Transpl., 2009, 15, 330-340.

[38] Loftus, E.V., Jr.; Aguilar, H.I.; Sandborn, W.J.; Tremaine, W.J.; Krom, R.A.; Zinsmeister, A.R.; Graziadei, I.W.; Wiesner, R.H. Risk of colorectal neoplasia in patients with primary sclerosing cholangitis and ulcerative colitis following orthotopic liver transplantation. Hepatology, 1998, 27, 685-690.

[39] Bergquist, A.; Ekbom, A.; Olsson, R.; Kornfeldt, D.; Lööf, L.; Danielsson, A.; Hultcrantz, R.; Lindgren, S.; Prytz, H.; SandbergGertzén, H.; Almer, S.; Granath, F.; Broomé, U. Hepatic and extrahepatic malignancies in primary sclerosing cholangitis. $J$. Hepatol., 2002, 36, 321-327.

[40] Razumilava, N.; Gores, G.J.; Lindor, K.D. Cancer surveillance in patients with primary sclerosing cholangitis. Hepatology, 2011, 54, 1842-1852.

[41] Abbas, G.; Lindor, K.D. Cholangiocarcinoma in primary sclerosing cholangitis. J. Gastrointest. Cancer, 2009, 40, 19-25.

[42] Broome, U.; Löfberg, R.; Veress, B.; Eriksson, L.S. Primary sclerosing cholangitis and ulcerative colitis: evidence for increased neoplastic potential. Hepatology, 1995, 22, 1404-1408.

[43] Komichi, D.; Tazuma, S.; Nishioka, T.; Hyogo, H.; Chayama, K. Glycochenodeoxycholate plays a carcinogenic role in immortalized mouse cholangiocytes via oxidative DNA damage. Free Radic. Biol. Med., 2005, 39, 1418-1427.

[44] Meng, F.; Yamagiwa, Y.; Ueno, Y.; Patel, T. Over-expression of interleukin-6 enhances cell survival and transformed cell growth in human malignant cholangiocytes. J. Hepatol., 2006, 44, 10551065.

[45] Lazaridis, K.N.; Gores, G.J. Primary sclerosing cholangitis and cholangiocarcinoma. Semin. Liver Dis., 2006, 26, 42-51.

[46] Petersen-Benz, C.; Stiehl, A. Impact of dominant stenoses on the serum level of the tumor marker CA19-9 in patients with primary sclerosing cholangitis. Z. Gastroenterol., 2005, 43, 587-590.

[47] Levy, C.; Lymp, J.; Angulo, P.; Gores, G.J.; Larusso, N.; Lindor, K.D. The value of serum CA 19-9 in predicting cholangiocarcinomas in patients with primary sclerosing cholangitis. Dig. Dis. Sci., 2005, 50, 1734-1740.

[48] Nehls, O.; Gregor, M.; Klump, B. Serum and bile markers for cholangiocarcinoma. Semin. Liver Dis., 2004, 24, 139-154.

[49] Charatcharoenwitthaya, P.; Enders, F.B.; Halling, K.C.; Lindor, K.D. Utility of serum tumor markers, imaging, and biliary cytology for detecting cholangiocarcinoma in primary sclerosing cholangitis. Hepatology, 2008, 48, 1106-1117.

[50] Said, K.; Glaumann, H.; Bergquist, A. Gallbladder disease in patients with primary sclerosing cholangitis. J. Hepatol., 2008, 48, 598-605.

[51] Buckles, D.C.; Lindor, K D.; Larusso, N.F.; Petrovic, L.M.; Gores, G.J. In primary sclerosing cholangitis, gallbladder polyps are frequently malignant. Am. J. Gastroenterol., 2002, 97, 1138-1142.

[52] Bruix, J.; Sherman, M. Management of hepatocellular carcinoma: an update. Hepatology, 2011, 53, 1020-1022.

[53] Shetty, K.; Rybicki, L.; Brzezinski, A.; Carey, W.D.; Lashner, B.A. The risk for cancer or dysplasia in ulcerative colitis patients with 
primary sclerosing cholangitis. Am. J. Gastroenterol., 1999, 94, 1643-1649.

[54] Soetikno, R.M.; Lin, O.S.; Heidenreich, P.A.; Young, H.S.; Blackstone, M.O. Increased risk of colorectal neoplasia in patients with primary sclerosing cholangitis and ulcerative colitis: a metaanalysis. Gastrointest. Endosc., 2002, 56, 48-54.

[55] Braden, B.; Halliday, J.; Aryasingha, S.; Sharifi, Y.; Checchin, D.; Warren, B.F.; Kitiyakara, T.; Travis, S.P.; Chapman, R.W. Risk for Colorectal Neoplasia in Patients with Colonic Crohn's Disease and Concomitant Primary Sclerosing Cholangitis. Clin. Gastroenterol. Hepatol., 2012, 10, 303-308.

[56] Pekow, J.R.; Hetzel, J.T.; Rothe, J.A.; Hanauer, S.B.; Turner, J.R.; Hart, J.; Noffsinger, A.; Huo, D.; Rubin, D.T. Outcome after surveillance of low-grade and indefinite dysplasia in patients with ulcerative colitis. Inflamm. Bowel. Dis., 2010, 16, 1352-1356.

[57] Post, A.B.; Bozdech, J.M.; Lavery, I.; Barnes, D.S. Colectomy in patients with inflammatory bowel disease and primary sclerosing cholangitis. Dis. Colon. Rectum., 1994, 37, 175-178.

[58] Broome, U.; Bergquist, A. Primary sclerosing cholangitis, inflammatory bowel disease, and colon cancer. Semin. Liver Dis., 2006, 26, 31-41.

[59] Wiesner, R.H.; LaRusso, N.F.; Dozois, R.R.; Beaver, S.J. Peristomal varices after proctocolectomy in patients with primary sclerosing cholangitis. Gastroenterology, 1986, 90, 316-322.

[60] Gillen, C.D.; Walmsley, R.S.; Prior, P.; Andrews, H.A.; Allan, R.N. Ulcerative colitis and Crohn's disease: a comparison of the colorectal cancer risk in extensive colitis. Gut, 1994, 35, 15901592.

[61] Lai, E.C.; Mok, F.P.; Tan, E.S.; Lo, C.M.; Fan, S.T.; You, K.T.; Wong, J. Endoscopic biliary drainage for severe acute cholangitis. N. Engl. J. Med., 1992, 326, 1582-1586.

[62] Lee, J.G. Diagnosis and management of acute cholangitis. Nat. Rev. Gastroenterol. Hepatol., 2009, 6, 533-541.

[63] Okolicsanyi, L.; Fabris, L.; Viaggi, S.; Carulli, N.; Podda, M.; Ricci, G. Primary sclerosing cholangitis: clinical presentation, natural history and prognostic variables: an Italian multicentre study. The Italian PSC Study Group. Eur. J. Gastroenterol. Hepatol., 1996, 8, 685-691.

[64] Rudolph, G.; Gotthardt, D.; Klöters-Plachky, P.; Kulaksiz, H.; Rost, D.; Stiehl, A. Influence of dominant bile duct stenoses and biliary infections on outcome in primary sclerosing cholangitis. $J$. Hepatol., 2009, 51, 149-155.

[65] Abraham, S.C.; Kamath, P.S.; Eghtesad, B.; Demetris, A.J.; Krasinskas, A.M. Liver transplantation in pre-cirrhotic biliary tract disease: Portal hypertension is frequently associated with nodular regenerative hyperplasia and obliterative portal venopathy. Am. J. Surg. Pathol., 2006, 30, 1454-1461.

[66] Lindor, K.D. Ursodiol for primary sclerosing cholangitis. Mayo Primary Sclerosing Cholangitis-Ursodeoxycholic Acid Study Group. N. Engl. J. Med., 1997, 336, 691-695.

[67] Lindor KD, Gershwin ME, Poupon R, Kaplan M, Bergasa NV, Heathcote EJ. Primary biliary cirrhosis. Hepatology, 2009, 50, 291308.

[68] Lindor, K.D.; Kowdley, K.V.; Luketic, V.A.; Harrison, M.E.; McCashland, T.; Befeler, A.S.; Harnois, D.; Jorgensen, R.; Petz, J.; Keach, J.; Mooney, J.; Sargeant, C.; Braaten, J.; Bernard, T.; King, D.; Miceli, E.; Schmoll, J.; Hoskin, T.; Thapa, P.; Enders, F. Highdose ursodeoxycholic acid for the treatment of primary sclerosing cholangitis. Hepatology, 2009, 50, 808-814.

[69] Eaton, J.E.; Silveira, M.G.; Pardi, D.S.; Sinakos, E.; Kowdley, K.V.; Luketic, V.A.; Harrison, M.E.; McCashland, T.; Befeler, A.S.; Harnois, D.; Jorgensen, R.; Petz, J.; Lindor, K.D. High-dose ursodeoxycholic acid is associated with the development of colorectal neoplasia in patients with ulcerative colitis and primary sclerosing cholangitis. Am. J. Gastroenterol., 2011, 106, 16381645.

[70] Poropat, G.; Giljaca, V.; Stimac, D.; Gluud, C. Bile acids for primary sclerosing cholangitis. Cochrane. Database Syst. Rev., 2011, 19(1), CD003626.
[71] Triantos, C.K.; Koukias, N.M.; Nikolopoulou, V.N.; Burroughs, A.K. Meta-analysis: ursodeoxycholic acid for primary sclerosing cholangitis. Aliment. Pharmacol. Ther., 2011, 34, 901-910.

[72] LaRusso, N.F.; Shneider, B.L.; Black, D.; Gores, G.J.; James, S.P.; Doo, E.; Hoofnagle, J.H. Primary sclerosing cholangitis: summary of a workshop. Hepatology, 2006, 44, 746-764.

[73] Stiehl, A. Primary sclerosing cholangitis: the role of endoscopic therapy. Semin. Liver Dis., 2006, 26, 62-68.

[74] Kim, W.R.; Therneau, T.M.; Wiesner, R.H.; Poterucha, J.J.; Benson, J.T.; Malinchoc, M.; LaRusso, N.F.; Lindor, K.D.; Dickson, E.R. A revised natural history model for primary sclerosing cholangitis. Mayo. Clin. Proc., 2000, 75, 688-694.

[75] Baluyut, A.R.; Sherman, S.; Lehman, G.A.; Hoen, H.; Chalasani, N. Impact of endoscopic therapy on the survival of patients with primary sclerosing cholangitis. Gastrointest. Endosc., 2001, 53, 308-312.

[76] Gluck, M.; Cantone, N.R.; Brandabur, J.J.; Patterson, D.J.; Bredfeldt, J.E.; Kozarek, R.A. A twenty-year experience with endoscopic therapy for symptomatic primary sclerosing cholangitis. J. Clin. Gastroenterol., 2008, 42, 1032-1039.

[77] Graziadei, I.W.; Wiesner, R.H.; Marotta, P.J.; Porayko, M.K.; Hay, J.E.; Charlton, M.R.; Poterucha, J.J.; Rosen, C.B.; Gores, G.J.; LaRusso, N.F.; Krom, R.A. Long-term results of patients undergoing liver transplantation for primary sclerosing cholangitis. Hepatology, 1999, 30, 1121-1127.

[78] Graziadei, I.W.; Wiesner, R.H.; Batts, K.P.; Marotta, P.J.; LaRusso, N.F.; Porayko, M.K.; Hay, J.E.; Gores, G.J.; Charlton, M.R.; Ludwig, J.; Poterucha, J.J.; Steers, J.L.; Krom, R.A. Recurrence of primary sclerosing cholangitis following liver transplantation. Hepatology, 1999, 29, 1050-1056.

[79] Cullen, S.N.; Chapman, R.W. Current management of primary sclerosing cholangitis. Aliment. Pharmacol. Ther., 2005, 21, 933948.

[80] Welsh, F.K.; Wigmore, S.J. Roux-en-Y Choledochojejunostomy is the method of choice for biliary reconstruction in liver transplantation for primary sclerosing cholangitis. Transplantation, 2004, 77, 602-604.

[81] Wiesner, R.H.; Porayko, M.K.; Dickson, E.R.; Gores, G.J.; LaRusso, N.F.; Hay, J.E.; Wahlstrom, H.E.; Krom, R.A. Selection and timing of liver transplantation in primary biliary cirrhosis and primary sclerosing cholangitis. Hepatology, 1992, 16, 1290-1299.

[82] Tischendorf, J.J.; Hecker, H.; Kruger, M.; Manns, M.P.; Meier, P.N. Characterization, outcome, and prognosis in 273 patients with primary sclerosing cholangitis: a single center study. Am. J. Gastroenterol., 2007, 102, 107-114.

[83] Tischendorf, J.J.; Meier, P.N.; Strassburg, C.P.; Klempnauer, J.; Hecker, H.; Manns, M.P.; Krüger, M. Characterization and clinical course of hepatobiliary carcinoma in patients with primary sclerosing cholangitis. Scand. J. Gastroenterol., 2006, 41, 12271234.

[84] Rosen, C.B.; Heimbach, J.K.; Gores, G.J. Liver transplantation for cholangiocarcinoma. Transpl. Int., 2010, 23, 692-697.

[85] Rea, D.J.; Heimbach, J.K.; Rosen, C.B.; Haddock, M.G.; Alberts, S.R.; Kremers, W.K.; Gores, G.J.; Nagorney, D.M. Liver transplantation with neoadjuvant chemoradiation is more effective than resection for hilar cholangiocarcinoma. Ann. Surg., 2005, 242, 451-458.

[86] Ngu, J.H.; Gearry, R.B.; Frampton, C.M.; Stedman, C.A. Mortality and the risk of malignancy in autoimmune liver diseases: A population-based study in Canterbury, New Zealand. Hepatology, 2012, 55, 522-529.

[87] Kim, W.R.; Poterucha, J.J.; Wiesner, R.H.; LaRusso, N.F.; Lindor, K.D.; Petz, J.; Therneau, T.M.; Malinchoc, M.; Dickson, E.R. The relative role of the Child-Pugh classification and the Mayo natural history model in the assessment of survival in patients with primary sclerosing cholangitis. Hepatology, 1999, 29, 1643-1648. 